\section{SM Gerontology and Geriatric Research}

Article Information

Received date: Apr 10, 2017

Accepted date: May 22, 2017

Published date: May 29, 2017

*Corresponding author

Alexandra D. Hill, Department of Physical and Occupational Therapy, Duke University Health System, Durham, NC, USA,

Tel: 919-206-4888; Fax: 919-206-4860; Email: alexandra.d.hill@duke.edu

Distributed under Creative Commons CC-BY 4.0

Keywords Falls; Falls assessments; Fall risk; Urinary incontinence; Geriatric

Abbreviations Qol: Quality of Life; UI: Urinary Incontinence; CDC: Center for Disease Control; AGS: American Geriatric Society; USPSTF: United States Preventative Services Task Force; APTA: American Physical Therapy Association; AGPT: Academy of Geriatric Physical Therapy; CST: 30 Second Chair Stand Test; POMA: Performance Oriented Mobility Assessment; TUG: Timed Up-And-Go Test; FRT: Functional Reach Test; BBS: Berg Balance Scale; DGI: Dynamic Gait Index; FES: Falls Efficacy Scale; ADL: Activity of Daily Living; SLS: Single Leg Stance; SSWS: Self-Selected Walking Speed; CVAMC: Cincinnati Veterans Affairs Medical Center

Article DOI 10.36876/smggr.1002

\section{OPEN ACCESS}

\section{ISSN: 2576-5434}

Research Article

\section{Preliminary Case Series in Veteran Population Relating Urinary Incontinence to Functional Fall Risk}

\section{Assessments}

\author{
Casey M Turner ${ }^{1}$, Alexandra D Hill ${ }^{2 \star}$ and Thomas J Sauer ${ }^{3}$ \\ ${ }^{1}$ Department of Physical Medicine, Durham VA Health Care System, USA \\ ${ }^{2}$ Department of Physical and Occupational Therapy, Duke University Health System, USA \\ ${ }^{3}$ Department of Radiology, Medical Physics Graduate Program, Carl E. Ravin Advanced Imaging \\ Laboratories Duke University, USA
}

\section{Abstract}

Urinary incontinence and falls are prevalent health conditions in the older population. Although there are many recommended functional falls assessments available, there is lacking evidence on the use of $\mathrm{UI}$ for falls screenings. This paper includes a mini review on urinary incontinence and falls assessments in the older population, and a preliminary case series investigating the relationship between $\mathrm{UI}$ and functional falls assessments. Analysis of sex and UI suggests that sex and urinary incontinence are not independent over the age of $65(p=0.1667)$. Urinary incontinence and fall risk per functional measure were strongly rank-correlated for the under 65 population $(\rho=1, p=0.1333)$, as were UI and TUG score $(\rho=0.8281, p=0.1333)$, and total number of fall risk factors and fall risk per functional measure $(\rho=0.8402, p=0.1333)$. In the participants under 65 years old, those with UI have a tendency to demonstrate higher TUG scores and a higher likelihood of being identified as a potential faller; the under 65 cohort also demonstrates a higher number of risk factors when testing positively on the included functional fall measures.

\section{Introduction}

The elderly population is an exponentially growing portion of the population encountered in healthcare facilities. It is known that older adults have a higher prevalence of comorbidities, experience age-related physiological changes and demonstrate associated impaired function and potentially increased fall risk [1-4]. Urinary Incontinence (UI) is a prevalent comorbidity among older adults and can contribute to falls. Additionally, falls are a significant source of morbidity and mortality in the older population. There is an abundance of literature describing functional assessments to determine fall risk in community-dwelling older adults, but there is lacking evidence supporting the presence of UI as a fall risk factor [5]. In this paper, a mini review of UI and fall risk factors for older adults is presented. This mini review lends itself to support the basis of the preliminary case series performed, which examines the association of UI and functional fall risk assessments in community-dwelling veteran older adults.

\section{Urinary Incontinence in the Older Adult}

Urinary incontinence, or unwanted leakage of urine, is associated with functional decline, decreased Quality of Life (QoL), and increased risk for morbidity in the older population. It is often a result of multiple risk factors including pathological, physiological, and functional changes [6]. The main types of UI are stress UI (involuntary loss of urine on effort or physical exertion), urge UI (involuntary loss of urine associated with urgency), and mixed UI (a combination of stress and urge UI) [7]. Age-related physiologic changes in the lower urinary tract, such as decreased sensation of bladder fill, decreased bladder contractility, atrophy of pelvic floor muscles, and increased post-void residual volumes, can predispose older persons to experience UI [8]. Other factors that can lead to an increased risk of UI in older adults include polypharmacy and increased comorbidities such as stroke or diabetes. Compared to younger populations, UI in older adults is more likely to be related to other health problems including dementia, urinary tract infection, being bedridden, hygienic and skin problems, and cognitive or physical impairment [9-12].

Epidemiological studies show the prevalence of UI increases with age, though rates vary between studies often due to differences in target population and definition of UI. A multinational study found that among men, the prevalence increases from $2.4 \%$ in those less than 39 years old to $10.4 \%$ in those greater than 60 years old; in women, the prevalence increases from $7.3 \%$ to $19.3 \%$, respectively [13]. Other studies have reported UI prevalence rates in community-dwelling older persons as 
$15-35 \%$ [14], and up to $41 \%$ of older men and $31 \%$ of older women experiencing urgency UI $[15,16]$. Beyond the increased prevalence of UI in older adults, this population also experiences more severe symptoms and consequences not seen in younger populations such as fall risk, fracture, increased caregiver burden, institutionalism, and hospitalization $[9,17-20]$.

Urgency UI has been found to be the most common type among older adults $[16,21]$. Studies examining health care costs associated with urgency UI in varying age ranges have reported substantial economic burden, with one US based study reporting a total cost of $\$ 66$ billion in 2007 [22]. In addition to the high economic burden of UI, it is important to note the significant impact UI has on QoL in the older population. Urinary incontinence in older adults has been associated with depression, anxiety, decreased self-esteem, decreased physical activity, decreased sexual function, social isolation, and increased risk of death [10-12,23-25]. Studies have found that many of these health conditions associated with UI can increase fall risk [2,26-28].

Falls are the primary cause of hip fracture, the most common cause for traumatic brain injury, and are the leading cause of death from injury in older adults $[3,29]$. The etiology of falls is multifactorial and it has been reported that the strongest predictors of falls are a recent fall and the presence of a gait or balance disorder [30]. It would be remiss, however, to discount UI as a significant factor in falls among older adults. Previous studies have found that older communitydwelling adults experiencing urge UI are more likely to fall compared to age-matched controls, with an odds ratio for falls ranging 1.5 to 2.3 $[17,19]$. Moreover, weekly or more urge UI among older communitydwelling women independently increases the risk of falls by $26 \%$ and the risk of fractures by $34 \%$ [17]. It has been hypothesized that the relationship of urgency UI and increased fall risk is related to rushing to the toilet and distressing emotions after not being able to reach the toilet without UI occurring, though there is lacking evidence to support this thought $[17,31,32]$. Increased frequency of nighttime voiding in itself can increase the risk of falls, as there is an increased number of opportunities to fall compared to no or minimal urinary frequency at nighttime $[17,19]$. The presence of impaired balance, muscle weakness, abnormal gait pattern, and impaired cognition are commonly seen in the older population; as one would anticipate, these have a negative impact on an older person's ability to safely get to the bathroom. Furthermore, it is known that dual-tasking, or trying to do two things simultaneously, is associated with falls; in the event of an older person attempting to walk to the bathroom, prevent UI, and navigate the home, multi-tasking is needed and this may have a negative impact on a person's ability to maintain their balance [3335].

Despite evidence showing high prevalence rates of UI in the older population, nearly half of patients with UI do not seek help for their symptoms $[36,37]$. This ultimately leads to UI being under-diagnosed and under-treated. Patients do not discuss their UI concerns with health care providers for various reasons, including embarrassment, misconception of UI being a natural part of aging, perceived stigma, and misconception that there are no available treatments that are effective $[8,12]$.

With the increased risk for falls associated with a diagnosis of UI, coupled with a large majority of patients not discussing their UI concerns with health care providers, it is imperative to screen for UI as a fall risk in the older population. The following section will highlight recommended functional falls assessments.

\section{Functional Falls Assessments}

An abundance of screenings and multifactorial assessments exist to identify potential fallers in the community-dwelling older adult population. Many resources are available from the Center for Disease Control (CDC), American Geriatric Society (AGS), United States Preventative Services Task Force (USPSTF), American Physical Therapy Association (APTA), and Academy of Geriatric Physical Therapy (AGPT) regarding recommendations for falls assessment. This section will examine current and highly cited literature regarding falls assessments from the above stated sources.

A nationwide falls coalition for earlier identification of potential fallers during patients' primary health care encounter has been initiated in order to address the growing prevalence of falls in the older adult. The CDC STEADI (Stopping Elderly Accidents, Deaths and Injuries) tool kit is a resource focused on fall prevention in older adults. Current recommendations from the CDC STEADI initiative encourage primary care providers to ask the following questions: 1) have you fallen in the past year; 2) do you feel unsteady when standing or walking; 3) do you worry about falling [32]. If a patient answers yes to any of these screening questions, the patient should be further assessed with three functional screening tools: Timed Up and Go Test (TUG), 30 Second Chair Stand Test (CST) and 4 Stage Balance Test [38].

The AGS and USPSTF recommend primary care clinicians to screen patients yearly for fall risk. "A multifactorial risk assessment with multicomponent intervention" is recommended for "older adults who have had 2 falls in the past year ( 1 fall if combined with gait or balance problems, have gait or balance problems or present with an acute fall)" [39-43]. Some recommended tools from the USPTF are: "the Falls Risk Assessment Tool, the Performance Oriented Mobility Assessment (POMA), the Timed Get-up-and-Go test (TUG), the Falls Risk Assessment Score for the Elderly, the Functional Reach Test (FRT) and the Berg Balance Scale (BBS)" [39-43].

The APTA and the AGPT have also released a literature summary entitled Physical Fitness and Falls Risk Reduction Based on Best Available Evidence, which recommends the BBS, TUG, POMA and Dynamic Gait Index (DGI) as functional measures [44-52]. In addition, self-report subjective measures are recommended to identify patient perceived fall risk; the literature summary recommends the Falls Efficacy Scale (FES) and the Activities-specific Balance Confidence (ABC) Scale [53,54].

Several of the previously described tests recurred many times in the various fall prevention organizations' recommendations for functional assessments of fall risks. Furthermore, literature and systematic reviews also consistently recommend the same subjective measures stated above. Lusardi et al. summarized via systematic review and meta-analysis posttest probability of tools used to determine risk of falls in community-dwelling older adults. This study found medical history screening questions regarding previous falls, taking psychoactive medications, requiring assistance for any Activity of Daily Living (ADL), being fearful of falling and using an ambulatory assistive device, all increased posttest probability for identifying 
potential fallers with positive response [55]. Self-report measures of Falls Risk Assessment Questionnaire, Balance Self-Perception Test, ABC Scale, and FES International demonstrated the largest increase in posttest probability with the FES receiving the highest evidentiary support. Lusardi et al. also reported other self-report measures of interest and benefit which included the Barthel Index for ADL participation, Older Adults Resources and Services, Mini Mental State Evaluation, Geriatric Depression scale-15, the Center for Epidemiological Studies Depression scale and the Longitudinal Study of Aging Physical Activity Questionnaire [55]. Performancebased measures recommended for largest increase in posttest probability include the BBS, TUG, Single Leg Stance (SLS), 5 times sit to stand, POMA and Self-Selected Walking Speed (SSWS); the DGI failed to have sufficient supporting evidence for recommendations [55]. A systematic review by Scott et al. recommends the following multifactorial and functional mobility assessment tools for fall risk among older adults in the community setting based on sensitivity and specificity greater than 70\%: 5 minute walk, the five-step test and the FRT [43]. The Clinical Test for Sensory Integration of Balance, floor transfer test, and maximum step length are three other tools in this review with high predictive value not measured via sensitivity and specificity. According to Perell et al. in the outpatient setting, the TUG and Elderly Fall Screening Test are effective fall risk assessments for mobility and balance; the BBS, DGI, and POMA also demonstrated greater than $75 \%$ sensitivity and all but the DGI greater than $74 \%$ specificity [56].

Consistently through literature and systematic reviews and fall prevention organizations' recommendations, the TUG, BBS, POMA, FES and FRT are recommended for assessment of fall risk factors. Medical history screening questions regarding history of falls, use of assistive devices, and fear of falling are encouraged. The TUG in particular is of valid clinical utilization as multiple studies have correlated the TUG to gait speed/SSWS, POMA, and ADL scale for predictability of falls $[42,57,58]$ and shown via psychometric properties as the most appropriate tool along with the POMA for evaluating fall risk in the community-dwelling older adult [58]. The TUG also possesses established normative data for communitydwelling adults [48,59], good-excellent test-retest reliability [42,59], good inter rater reliability [42], and adequate construct validity [58].

One functional measure of relevance to this study that has only been mentioned once previously is the 30 second Chair Stand Test (CST). While the literature and systematic reviews included did not provide recommendations for the CST, this measure offers an assessment of lower extremity functional strength in a time effective manner. Additionally, it is easily combined with other short functional measures for a cumulative examination of gait and mobility. The benefit of using the CST as opposed to other sit to stand tests is the avoidance of a floor effect unlike the 5 or 10 times sit to stand. The Jones et al. study on use of the CST in community-dwelling elderly demonstrates age, activity level and gender matched normative data, excellent test-retest reliability, excellent inter rater reliability, and excellent criterion validity [60].

In summary, there are multiple reliable, specific, sensitive and recommended measures for identifying potential fallers. Functional measures should be selected based on patient response to screening questions, patient specific history and observation. Availability of resources, including time at the clinical encounter, should also be factors. High recommendations also stand for completion of the FES as a self-report measure.

Studies have shown that UI is associated with increased fall risk in older adults, and there is also evidence supporting the use of functional falls screens or assessments in the older population. To the authors' knowledge, there are no cited studies correlating UI to functional falls screens or assessments. The following case series analysis aims to provide preliminary insight into the relationship of falls and UI in the community-dwelling older adult.

\section{Case Series Overview}

A 2014 study by Hirase et al. examined the relationship between a modified fall risk assessment tool and physical functional assessments. The aim of the study was to identify those items on a falls assessment questionnaire that "could predict falls and estimate the physical function of high-risk fallers" [61].The study found predictive value in questions regarding history of falls, gait performance, SLS, recent hospitalization, history of stroke, and fear of falling as fall risk factors as determined by the CST and TUG [61]. This study model was utilized in the structuring of this case series which was conducted at the Cincinnati Veterans Affairs Medical Center (CVAMC). The goal of the Cincinnati case series was to examine the ability of selected risk factors via questionnaire to predict functional fall risk.

\begin{tabular}{|l|l|l|}
\hline \multicolumn{2}{|c|}{ Falls Screening Questionnaire } \\
\hline Falls Prevention Fair 2014 & \multicolumn{1}{|c|}{ Yes } & \\
\hline & & \\
\hline Are you over the age of 65? & & \\
\hline Have you fallen in the past year? & & \\
\hline Do you have a fear of falling? & & \\
\hline Do you wear glasses? & & \\
\hline Do you take multiple medications? & & \\
\hline Have you had a loss/change of sensation in your feet? & & \\
\hline Do you have bladder control issues? & & \\
\hline Do you exercise? & & \\
\hline Have you been diagnosed with cardiovascular related \\
diseases?
\end{tabular}

Figure 1: Falls screening questionnaire. 


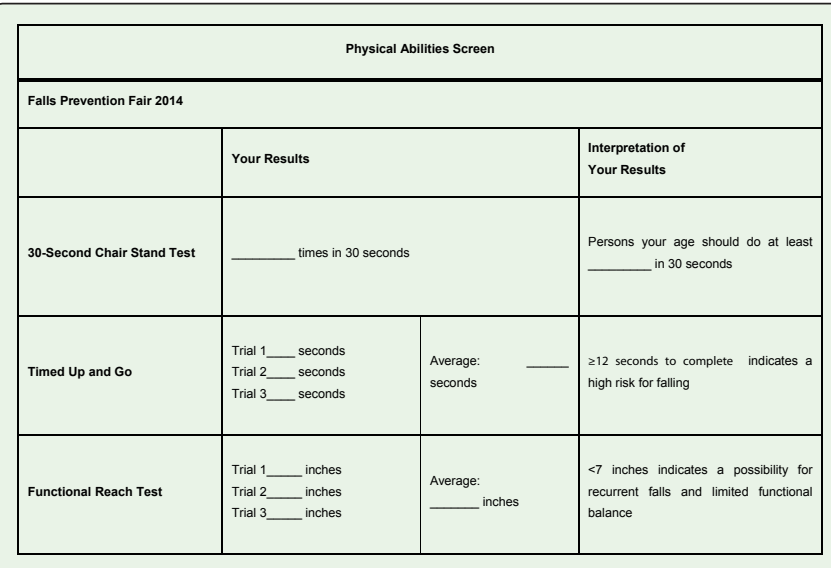

Figure 2: Physical abilities screen scoring sheet.

\section{Case Series Method}

The CVAMC physical therapy department conducted a singleday falls screening fair in Fall 2014. Patients, caregivers and providers were encouraged to attend for education and falls screenings for potential fallers. Data were collected from this event from voluntary participants who were veterans. The falls screening was conducted in a 2 -step process. First, voluntary participants completed a questionnaire (Figure 1) of risk factors compiled from the Hirase et al. article, the Desmond Fall Risk Questionnaire and the CDC Fall Risk Checklist. Questions included on the falls screening fair questionnaire were selected based on clinical prevalence observed in the geriatric physical therapy population at the CVAMC. The questions were answered with a yes/no response for the following potential risk factors for falls: age greater than 65 years, history of falls, fear of falling, vision impairment, polypharmacy, impaired lower extremity sensation, UI, activity level, cardiovascular disease, smoking, use of an assistive device, environmental hazards and depression.

After completing the questionnaire, participants completed 3 functional falls screens: TUG, CST, and FRT. These functional fall screens were chosen based on the aforementioned research support, timeliness to complete and diversity of functional abilities assessed (Figure 2).

\section{Case Series Results}

Thirteen individuals participated in the functional fall risk assessment. Twelve of the thirteen participants completed the questionnaire portion, and all thirteen participants were veterans. Individual responses and functional measures scores can be found in Table 1. Relationships between risk factors and functional measures were analyzed from the case series. For this case series, relationships between UI, gender, functional fall risk, and age groups over and under age 65 were of primary concern.

The case series included 2 females and 11 males. Seven of the 13 (53.8\%) participants were under the age of 65 , with an average age of 55.4 years. One participant under 65 was the individual who declined completing the falls risk questionnaire. The CST deemed that all seven participants under the age of 65 were potential fallers; two (28.6\%) of whom were also identified as fall risks via the TUG. The total number of fall risk factors ranged from 1-11 with an average of 6.1 . The most common risk factor for falls for those under the age of 65 was polypharmacy. No exercise, environmental hazards, depression, smoking, glasses and history of falling followed polypharmacy equally. The CST scores ranged from 4-8 repetitions with an average of 9.1 repetitions.

Table 1: Participant responses and functional test scores.

\begin{tabular}{|c|c|c|c|c|c|c|c|c|c|c|c|c|c|c|c|c|c|c|c|c|}
\hline 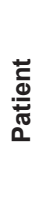 & $\begin{array}{l}\frac{1}{\Lambda} \\
\frac{\pi}{\Lambda}\end{array}$ & $\begin{array}{l}\overline{\bar{N}} \\
\frac{\overleftarrow{0}}{0} \\
x \\
x\end{array}$ & 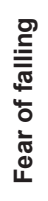 & 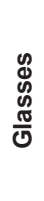 & 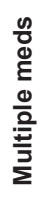 & 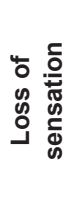 & 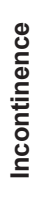 & $\begin{array}{l}.0 \\
\frac{.0}{0} \\
\frac{0}{0} \\
x \\
\dot{x}\end{array}$ & 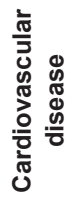 & 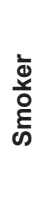 & 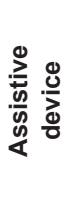 & $\begin{array}{l}\frac{n}{0} \\
\frac{0}{\pi} \\
\text { ֻ } \\
\frac{c}{2} \\
\frac{0}{4}\end{array}$ & $\begin{array}{l}\frac{.}{0} \\
0 \\
0 \\
\frac{0}{0} \\
0\end{array}$ & 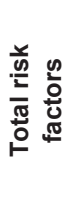 & 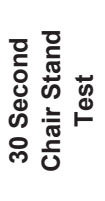 & 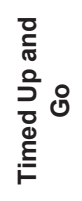 & 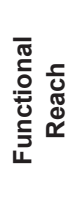 & $\stackrel{0}{ه}$ & હ & 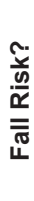 \\
\hline 1 & $\mathrm{~N}$ & $Y$ & $Y$ & $Y$ & $Y$ & $Y$ & $Y$ & $Y$ & $Y$ & $Y$ & $Y$ & $Y$ & $Y$ & 11 & 4 & 17.5 & 15.5 & 59 & $M$ & $Y$ \\
\hline 2 & $\mathrm{~N}$ & $Y$ & $Y$ & $\mathrm{~N}$ & $Y$ & $\mathrm{~N}$ & $\mathrm{~N}$ & $\mathrm{~N}$ & $\mathrm{~N}$ & $Y$ & $\mathrm{~N}$ & $\mathrm{~N}$ & $Y$ & 6 & 8 & 10.5 & 13.5 & 45 & $M$ & $Y$ \\
\hline 3 & $\mathrm{~N}$ & $\mathrm{~N}$ & $\mathrm{~N}$ & $\mathrm{~N}$ & $Y$ & $\mathrm{~N}$ & $\mathrm{~N}$ & $Y$ & $\mathrm{~N}$ & $\mathrm{~N}$ & $\mathrm{~N}$ & $\mathrm{~N}$ & $\mathrm{~N}$ & 1 & 4 & 9.4 & 9 & 58 & $M$ & $Y$ \\
\hline 4 & $\mathrm{Y}$ & $\mathrm{N}$ & $\mathrm{N}$ & $Y$ & $\mathrm{~N}$ & $Y$ & $\mathrm{~N}$ & $\mathrm{~N}$ & $\mathrm{~N}$ & $\mathrm{~N}$ & $Y$ & $Y$ & $\mathrm{~N}$ & 6 & 16 & 11.19 & 13 & 79 & $\mathrm{~F}$ & $\mathrm{~N}$ \\
\hline 5 & $\mathrm{~N}$ & $Y$ & $\mathrm{~N}$ & $Y$ & $Y$ & $\mathrm{~N}$ & $Y$ & $\mathrm{~N}$ & $\mathrm{~N}$ & $Y$ & $Y$ & $Y$ & $Y$ & 9 & 8 & 16 & 9 & 54 & $M$ & $Y$ \\
\hline 6 & $\mathrm{~N}$ & $Y$ & $\mathrm{~N}$ & $Y$ & $Y$ & $\mathrm{~N}$ & $\mathrm{~N}$ & $\mathrm{~N}$ & $\mathrm{~N}$ & $Y$ & $\mathrm{~N}$ & $Y$ & $Y$ & 7 & 12 & 8.7 & 8 & 52 & $\mathrm{~F}$ & $Y$ \\
\hline 7 & na & na & na & na & na & na & na & na & na & na & na & na & na & na & 16 & 6.67 & 12.25 & 57 & $M$ & $Y$ \\
\hline 8 & $Y$ & $\mathrm{~N}$ & $N$ & $Y$ & $Y$ & $\mathrm{~N}$ & $Y$ & $Y$ & $\mathrm{~N}$ & $\mathrm{~N}$ & $\mathrm{~N}$ & $\mathrm{~N}$ & $\mathrm{~N}$ & 4 & 14 & 10.18 & 15.5 & 69 & $M$ & $Y$ \\
\hline 9 & $\mathrm{~N}$ & $\mathrm{~N}$ & $\mathrm{~N}$ & $Y$ & $Y$ & $\mathrm{~N}$ & $\mathrm{~N}$ & $\mathrm{~N}$ & $\mathrm{~N}$ & $\mathrm{~N}$ & $\mathrm{~N}$ & $Y$ & $\mathrm{~N}$ & 6 & 12 & 6.4 & 11.5 & 63 & $M$ & $Y$ \\
\hline 10 & $Y$ & $\mathrm{~N}$ & $\mathrm{~N}$ & $Y$ & $Y$ & $Y$ & $Y$ & $\mathrm{~N}$ & $Y$ & $\mathrm{~N}$ & $\mathrm{~N}$ & $N$ & $\mathrm{~N}$ & 6 & 12 & 7.39 & 19.25 & 70 & $M$ & $Y$ \\
\hline 11 & $\mathrm{Y}$ & $Y$ & $Y$ & $Y$ & $\mathrm{~N}$ & $\mathrm{~N}$ & $Y$ & $\mathrm{~N}$ & $\mathrm{~N}$ & $\mathrm{~N}$ & $\mathrm{~N}$ & $Y$ & $\mathrm{~N}$ & 7 & 12 & 7.75 & 12 & 65 & $M$ & $Y$ \\
\hline 12 & $Y$ & $\mathrm{~N}$ & $\mathrm{~N}$ & $Y$ & $Y$ & $Y$ & $Y$ & $Y$ & $\mathrm{~N}$ & $\mathrm{~N}$ & $\mathrm{~N}$ & $\mathrm{~N}$ & $\mathrm{~N}$ & 5 & $30+$ & 6.37 & 13 & 68 & M & $N$ \\
\hline 13 & $Y$ & $Y$ & $\mathrm{~N}$ & $Y$ & $Y$ & $\mathrm{~N}$ & $Y$ & $Y$ & $Y$ & $\mathrm{~N}$ & $\mathrm{~N}$ & $Y$ & $\mathrm{~N}$ & 7 & 12 & 9.37 & 15.75 & 66 & $M$ & $Y$ \\
\hline
\end{tabular}


Table 2: Summary of statistics relevant to the study.

\begin{tabular}{|c|c|c|c|}
\hline & Fall risk per functional measure & Urinary incontinence & Total number of risk factors \\
\hline Sex & $\begin{array}{llllll}(0.3162, & 0.6325, & 0.3873 & \| & 1, & 0.6667 \\
0.2136) & & \end{array}$ & $(1,0.1667,0.1515)$ & \\
\hline $\begin{array}{l}\text { Fall Risk Per Functional } \\
\text { Measure }\end{array}$ & & $(1,0.6325,0.2928$ || 0.1333, 0.6667, 0.3558) & $\begin{array}{l}(0.8402,0.3198,0.6217 \| \\
0.6667)\end{array}$ \\
\hline Timed Up and Go & & $\begin{array}{l}(0.8281,-0.6547,-0.0245 \| \quad 0.1333,0.3333, \\
0.9398)\end{array}$ & $(0.6377,0,0.4287$ || $0.1944,0.1439,1)$ \\
\hline
\end{tabular}

Table key:

$\left.\tilde{n}_{<65}, \tilde{n}_{\geq 65}, \tilde{n}_{\text {all }} \| p_{<69} p_{\geq 65} p_{\text {all }}\right)=(a, b, c \| d, e, f)_{\text {a }}$

"all subjects", with their corresponding significance levels.

$\left.\tilde{n}_{<65}, \tilde{n}_{>65} \tilde{n}_{\text {all }}\right)=(g h \dot{i})$ are the results of Fisher's exact test.

The average age of the six participants over the age of 65 was 69.5 years. Four of these six $(66.7 \%)$ were deemed potential fallers via the CST only. Total number of risk factors ranged from 4-7 with an average of 5.8. The most common risk factors in the potential fallers were vision impairment and UI equally. The CST scores ranged from 12-30 repetitions with an average of 16 repetitions in all of the participants over the age of 65 and 12.5 repetitions in the potential fallers over the age of 65 . Overall, 11 of $13(84.6 \%)$ participants screened were found to be potential fallers on the CST. Two (15.4\%) were identified as potential fallers via the TUG and none were considered fallers via the FRT.

Relationships between patient attributes were examined for potential statistical significance in this cohort. For each statistical test conducted, the test was performed once with each member of the cohort as part of the statistical population as well as with the population dichotomized into "age 65 or older" and "under the age of 65 " groups. For the purpose of quantifying the independence of categorical variables, Fisher's exact test was used on the subset of cases for which $\div^{2}$-analysis would be appropriate with a larger cohort. For the purpose of quantifying the monotonicity of the rankorder of an ordinal, interval, or ratio variables as a function of the rank-order of another ordinal, interval, or ratio variable, Spearman's rank-order correlation was used. Note that some binary variables were considered to be ordinal within the context of the study, though they may not retain their natural order outside of this context.

There is a moderate rank-correlation between sex and fall risk per functional measure score for the entire cohort, $(\rho=0.3873, p=$ 0.2136 ), but a stronger rank-correlation for the over 65 population ( $\rho$ $=0.6325, p=0.6667)$. The correlation is indicative of a trend for men, specifically. Analysis of sex and UI suggests that sex and UI are not independent over the age of 65 ( $p=0.1667)$. Urinary incontinence and fall risk per functional measure were strongly rank-correlated for the under the age of 65 population $(\rho=1, p=0.1333)$, as were UI and TUG score $(\rho=0.8281, p=0.1333)$, and total number of fall risk factors and fall risk per functional measure $(\rho=0.8402, p=1.1333)$ Spearman's rho also identifies a significant rank-correlation between TUG score and number of fall risk factors for the entire cohort ( $\rho=$ $0.6377, p=0.1944$ ). The above results are summarized in Table 2 .

Analysis also yielded a dependence between the male sex and the presence of UI risk factor in those studied over the age of 65 ( $\mathrm{p}=$ 0.0143). The case series in those over the age of 65 demonstrates a nearly significant relationship between sex, UI and history of falls ( $p$ $=0.0582$ ). The most definitive dependent relationship in the series was present for males over 65 years of age with UI risk factor and 1 or more fall risks per functional measure $(\mathrm{p}=0.0010)$.

\section{Discussion}

The goal of this study is to examine the relationship between UI and fall risk in the community-dwelling veteran older adult. In this case series, dependent relationships have been identified between the risk factors of concern and fall risk per results of functional measures. In the under 65 sample, it can be stated that those with UI have a tendency to demonstrate higher TUG scores and a higher likelihood of being identified as a potential faller via the functional measures used in this case series. The younger sample also shows a higher number of risk factors when testing positively on the included functional fall measures. Trends in the over 65 population that warrant further investigation include combinations of dependent relationships between male sex-presence of UI, male sex-UI-history of falls, and male sex-UI-fall risk per functional measure. The last two statistical relationships support the study interest that an interaction between UI and fall risk may exist in the communitydwelling older adult male. While limited, previous studies also support the role of UI in increased fall risk in addition to urinary urgency, frequency and nocturia $[4,5,16,62-66]$. No other statistically significant trends were identified, including review of the other risk factors on the questionnaire. Of note, risk factors in the over 65 population including glasses and polypharmacy were not calculated because all of the participants were positive per functional measure for falling, clearly indicating a dependent relationship with falling. Multiple articles have established relationships between increased frequency of falling and medications that include psychotropics, blood pressure medications, anticonvulsants, sedatives, diuretics and many more [66-69]. It is likely that the increased prevalence of UI in the veteran population is impacted by increased comorbidities, higher level of medical complexity, and earlier debility [70]. These factors may also increase the functional deficits associated with UI in this population, both over and under the age of 65 . Fritel et al. reported a strong association between limitation of motor and balance skills and UI among older women utilizing functional tests [71]. This study, however, included only women in their sample. The veteran population has a much higher percentage of male than female patients; therefore, our study would suggest that UI is a factor worthy of attention clinically when assessing falls in veterans [72,73]. Falls in the veteran population are a result of many plausible risk factors. Urinary incontinence, particularly at nighttime, has anecdotally and statistically impacted the frequency of falls and potentials falls [19]. While many organizations recommend functional falls assessments, none have been directly correlated to UI as a risk factor. Additionally, none of the subjective screening questions recommended by falls prevention organizations (CDC, AGS, AGPT, and USPSTF) include 
UI as a positive referral tool for multifactorial falls assessment $[38,39,44]$. This may be because very little literature exists to support the relationship. The results of this case series propose further investigation to examine the importance of UI in veteran fallers and the use of UI as an identifier for potential fallers.

\section{Limitations of the Study}

There are many limitations to this preliminary case series. First, the data set is incomplete due to one participant who did not complete the questionnaire. Second, sample size of the case series is not large enough to provide statistically significant results to apply to the intended population. Additionally, selected functional screens, while time appropriate, may not be the most specific or sensitive tools for relating risk factors to functional fall risk as noted in the above review. In particular, the CST in this case series resulted in greater than $80 \%$ identification of potential fallers which may overestimate the actual percentage of fallers present in the sample assessed. However, it must be noted that the veteran population is reported as a generally sicker and more debilitated population and thus at a higher risk of falling due to increased comorbidities [70,72]. Finally, balancing practical application with optimal test findings is a limitation to be considered for future studies.

\section{Future Study Recommendations}

There are significant potential benefits for conducting this study in a much larger population with a control comparison for the veteran population. Also, because of the small sample size not all relationships for risk factors were capable of being examined statistically. As noted, the functional reach test did not identify any potential fallers and therefore may not be specific enough to replace subjective questionnaires for the identification of fallers.

\section{Acknowledgements}

The authors would like to thank Patricia Turner, Kathleen Hill, and Emily Kallen for their assistance with editing.

\section{References}

1. Rubenstein LZ. Falls in older people: epidemiology, risk factors and strategies for prevention. Age and ageing. 2006; 35: ii37-ii41.

2. Orr R. Contribution of muscle weakness to postural instability in the elderly. A systematic review. Eur J Phys Rehabil Med. 2010; 46: 183-220.

3. Beegan L, Messinger-Rapport BJ. Stand by me! Reducing the risk of injurious falls in older adults. Cleve Clin J Med. 2015; 82: 301-307.

4. Tromp AM, Pluijm SMF, Smit JH, Deeg DJH, Bouter LM, Lips P. Fall-risk screening test: a prospective study on predictors for falls in communitydwelling elderly. J Clin Epi. 2001; 54: 837-844.

5. De Rekeneire N, Visser M, Peila R, Nevitt MC, Cauley JA, Tylavsky FA, et al. Is a fall just a fall: correlates of falling in healthy older persons. The Health, Aging and Body Composition Study. J Am Geriatr Soc. 2013; 51: 841-846.

6. Gibson W, Wagg A. New horizons: urinary incontinence in older people. Age Ageing. 2014; 43: 157-163.

7. Haylen BT, de Ridder D, Freeman RM, Swift SE, Berghmans B, Lee J, et al. An International Urogynecological Association (IUGQ)/International Continence Society (ICS) joint report on the terminology for female pelvic floor dysfunction. Neurourol Urodyn. 2010; 29: 4-20.

8. Shaw C, Wagg A. Urinary incontinence in older adults. Medicine. 2017; 45: 23-27.
9. Aguilar-Navarro S, Navarrete-Reyes AP, Grados-Chavarria BH, GarcíaLara JMA, Amieva H, Avila-Funes JA. The severity of urinary incontinence decreases health-related quality of life among community-dwelling elderly. J Gerontol A Biol Sci Med Sci. 2012; 67: 1266-1271.

10. Saga S, Vinsnes AG, Mørkved S, Norton C, Seim A. What characteristics predispose to continence in nursing home residents? A population-based cross-sectional study. Neurourol Urodyn. 2015; 34: 362-367.

11. Offermans MP, Du Moulin MF, Hamers JP, Dassen T, Halfens RJ. Prevalence of urinary incontinence and associated risk factors in nursing home residents: a systematic review. Neurourol Urodyn. 2009; 28: 288-294.

12. Santos CR, Santos VL. Prevalence of self-reported double incontinence in the urban population of a Brazilian city. Neurourol Urodyn. 2011; 30: 14731479.

13. Irwin DE, Milsom I, Hunskaar S, Reilly K, Kopp Z, Herschorn S, et al. Population-based survey of urinary incontinence, overactive bladder, and other lower urinary tract symptoms in five countries: results of the EPIC study. Eur Urol. 2006; 50: 1306-1314.

14. Koskimaki J, Hakama M, Huhtala H, Tammela TL. Prevalence of lowe urinary tract symptoms in Finnish men: a population-based study. $\mathrm{Br} \mathrm{J}$ Urol. 1998; 81: 364-369.

15. Hannestad Y, Rortveit G, Sandvik H, Hunskaar. A community-based epidemiological survey of female urinary incontinence: The Norwegian EPINCONT study. J Clin Epidemiol. 2000; 53: 1150-1157.

16. Milsom I, Abrams P, Cardozo L, Roberts RG, Thüroff J, Wein AJ. How widespread are the symptoms of an overactive bladder and how are they managed? A population-based prevalence study. BJU International. 2001; 87: 760-766.

17. Brown JS, VittinghoffO E, Wyman JF, Stone KL, Nevitt MC, Ensrud KE, et al. Urinary incontinence: does it increase risk for falls and fractures? Study of Osteoporotic Fractures Research Group. J Am Geriatr Soc. 2000; 48: 721 725.

18. Thom DH, Haan MN, Van Den Eeden SK. Medically recognized urinary incontinence and risks of hospitalization, nursing home admission and mortality. Age Ageing. 1997; 26: 367-374.

19. Chiarelli PE, Mackenzie LA, Osmotherly PG. Urinary incontinence is associated with an increase in falls: a systematic review. Aust $\mathrm{J}$ Physiother. 2009; 55: 89-95.

20. Nuotio M, Tammela TL, Luukkaala T, Jylhä M. Predictors of institutionalization in an older population during a 13-year period: the effect of urge incontinence. J Gerontol A Biol Sci Med Sci. 2003; 58: 756-762.

21. Milsom I, Coyne KS, Nicholson S, Kvasz M, Chen C, Wein AJ. Global prevalence and economic burden of urgency urinary incontinence: a systematic review. Eur Urol. 2014; 65: 79-95.

22. Ganz ML, Smalarz AM, Krupski TL, Anger JT, Hu JC, Wittrup-Jensen KU, et al. Economic costs of overactive bladder in the United States. Urology. 2014; 75: $526-32,532$ e1-e18.

23. Grimby A, Milsom I, Molander U, Wiklund I, Ekelund P. The influence of urinary incontinence on the quality of life of elderly women. Age Ageing. 1993; 22: 82-89.

24. Abrams P, Kelleher CJ, Kerr LA, Rogers RG. Overactive bladder significantly affects quality of life. Am J Manag Care. 2000; 6: S580-S590.

25. Nakanishi N, Tatara K, Shinsho F, Murakami S, Takatorige T, Fukuda H, et al Mortality in relation to urinary and fecal incontinence in elderly people living at home. Age Ageing. 1999; 28: 301-306.

26. laboni A, Flint AJ. The complex interplay of depression and falls in older adults: a clinical review. Am J Geriatr Psychiatry. 2013; 21:484-492.

27. Delbourne K, Close JCT, Heim J, Sachdev P, Brodaty H, Slavin MJ, et al. A multifactorial approach to understanding fall risk in older people. J Am Geriatr Soc. 2010; 58: 1679-1685. 
28. Rossat A, Fantino B, Nitenberg C, Annweiler C, Poujol L, Herrmann FR, et al. Risk factors for falling in community-dwelling older adults: which of them are associated with the recurrence of falls? J Nutr Health Aging. 2010; 14 787-791.

29. Sterling DA, O'Connor JA, Bonadies J. Geriatric falls: injury severity is high and disproportionate to mechanism. J Trauma. 2001; 50: 116-119.

30. Ganz DA, Bao Y, Shekelle PG, Rubenstein LZ. Will my patient fall? JAMA 2007; 297: 77-86.

31. Miller $Y$, Brown $W$, Smith $N$, Chiarelli P. Managing urinary incontinence across the lifespan. Int J Behav Med. 2003; 10: 143-161.

32. Gibson W, Hunter KF, Camicioli R, Booth J, Skelton DA, Dumoulin C, et al. The association between lower urinary tract sypmtoms and falls: forming a theoretical model for a research agenda. Neurourol Urodyn. 2017; 1-9.

33. Foley AL, Loharuka S, Barrett JA, Mathews R, Wiliams K, McGrother CW, et al. Association between the Geriatric Giants of urinary incontinence and falls in older people using data from the Leicestershire MRC Incontinence Study. Age Ageing. 2012; 41: 35-40.

34. Beauchet O, Annweiler C, Allali G, Berrut G, Herrmann FR, Dubost V. Recurrent falls and dual task-related decreased in walking speed: is there a relationship? J Am Geriatr Soc. 2008; 56: 1265-1269.

35. Wolf SL, Riolo L, Ouslander JG. Urge incontinence and the risk of falling in older women. J Am Geratr Soc. 2000; 48: 847-848.

36. Teunissen D, van Weel C, Lagro-Janssen T. Urinary incontinence in older people living in the community: examining help-seeking behavior. $\mathrm{Br} \mathrm{J}$ Gen Pract. 2005; 55: 776-782

37. Dugan E, Roberts E, Cohen S, Preisser J, Davis C, Bland DR, et al. Why older community-dwelling adults do not discuss urinary incontinence with their primary care physicians. J Am Geriatr Soc. 2001; 49: 462-465.

38. Stevens JA. The STEADI Tool Kit: A Fall Prevention Resource for Health Care Providers. The IHS Primary Care Provider. 2013; 39: 162-166.

39. U.S. Preventive Services Task Force. 2016; Final Recommendation Statement: Falls Prevention in Older Adults: Counseling and Preventive Medication. Retrieved April 4, 2017, from https://www.uspreventiveservicestaskforce.org/ Page/Document/RecommendationStatementFinal/falls-prevention-in-olderadults-counseling-and-preventive-medication

40. Michael YL, Lin JS, Whitlock EP, Gold R, Fu R, O'Connor EA, et al. Interventions to prevent falls in older adults: an updated systematic review. Evidence Synthesis. 2010.

41. Mathias S, Nayak US, Isaacs B. Balance in elderly patients: the" get-up and go" test. Arch Phys Med. 1986; 67: 387-389.

42. Podsiadlo D, Richardson S. The timed "Up \& Go": a test of basic functional mobility for frail elderly persons. J Am Geriatr Soc. 1991; 39: 142-148.

43. Scott V, Votova K, Scanlan A, Close J. Multifactorial and functional mobility assessment tools for fall risk among older adults in community, homesupport, long-term and acute care settings. Age Ageing. 2007; 36: 130-139.

44. Section on Geriatrics and Neurology Section of the American Physical Therapy Association in partnership with the American Physical Therapy Association (2007) Physical Fitness and Falls Risk Reduction Based on Best Available Evidence. [PDF]. Alexandria: American Physical Therapy Association.

45. Berg K, Wood-Dauphine S, Williams JI, Gayton D. Measuring balance in the elderly: preliminary development of an instrument. Physiother Can. 1989; 41 304-311.

46. Berg KO, Maki BE, Williams, JI, Holliday PJ, Wood-Dauphinee SL. Clinical and laboratory measures of postural balance in an elderly population. Arch Phys Med. 1992; 73: 1073-1080.

47. Lajoie Y, Gallagher S. Predicting falls within the elderly community: comparison of postural sway, reaction time, the Berg balance scale and the Activities-specific Balance Confidence (ABC) scale for comparing fallers and non-fallers. Arch Gerontol Geriatr. 2004; 38: 11-26.
48. Shumway-Cook A, Brauer S, Woollacott M. Predicting the probability for falls in community-dwelling older adults using the Timed Up \& Go Test. Phys Ther. 2000; 80: 896-903.

49. Tinetti ME, Williams TF, Mayewski R. Fall risk index for elderly patients based on number of chronic disabilities. Am J Med. 1986; 80: 429-434.

50. Tinetti ME. Performance-oriented assessment of mobility problems in elderly patients. J Am Geriatr Soc. 1986; 34: 119-126.

51. Shumway-Cook A, Baldwin M, Polissar NL, Gruber W. Predicting the probability for falls in community-dwelling older adults. Phys Ther. 1997; 77: 812-819

52. Shumway-Cook A, Woollacott MH. Motor control: theory and practical applications. Lippincott Williams \& Wilkins. 1995; 323-324.

53. Tinetti ME, Richman D, Powell L. Falls efficacy as a measure of fear of falling J Gerontol. 1990; 45: P239-P243.

54. Powell, LE, \& Myers, AM. The activities-specific balance confidence (ABC) scale. J Gerontol A Biol Sci Med Sci. 1995; 50: M28-M34.

55. Lusardi MM, Fritz, S, Middleton A, Allison, L, Wingood, M, Phillips E, et al. Determining risk of falls in community dwelling older adults: a systematic review and meta-analysis using posttest probability. J Geriatr Phys Ther. 2017; 40: 1-36

56. Perell KL, Nelson A, Goldman RL, Luther SL, Prieto-Lewis N, Rubenstein LZ. Fall risk assessment measures an analytic review. J Gerontol A Biol Sci Med Sci. 2001; 56: M761-M766.

57. Viccaro LJ, Perera S, Studenski SA. Is timed up and go better than gait speed in predicting health, function, and falls in older adults? J Am Geriatr Soc. 2011; 59: 887-892.

58. Lin MR, Hwang HF, Hu MH, Wu HDI, Wang YW, Huang FC. Psychometric comparisons of the timed up and go, one-leg stand, functional reach, and Tinetti balance measures in community-dwelling older people. J Am Geriatr Soc. $2004 ; 52$ : $1343-1348$.

59. Steffen TM, Hacker TA, Mollinger L. Age-and gender-related test performance in community-dwelling elderly people: Six-minute walk test, Berg Balance Scale, Timed Up \& Go Test, and gait speeds. Phys Ther. 2002; 82: 128-137.

60. Jones CJ, Rikli RE, Beam WC. A 30-s chair-stand test as a measure of lowe body strength in community-residing older adults. Res Q Exerc Sport. 1999; 70: 113-119.

61. Hirase T, Inokuchi S, Matsusaka N, Nakahara K, Okita M. A modified fall risk assessment tool that is specific to physical function predicts falls in community-dwelling elderly people. J Geriatr Phys Ther. 2014; 37: 159-165.

62. Wei JT, Calhoun E, Jacobsen SJ. Urologic diseases in America project: benign prostatic hyperplasia. J Urol. 2005; 173: 1256-1261.

63. Trueman P, Hood SC, Nayak USL, Mrazek MF. Prevalence of lower urinary tract symptoms and self-reported diagnosed'benign prostatic hyperplasia', and their effect on quality of life in a community-based survey of men in the UK. BJU Int. 1999; 83: 410-415.

64. Boyle P, Robertson C, Mazzetta C, Keech M, Hobbs FDR, Fourcade R, et al. The prevalence of lower urinary tract symptoms in men and women in fou centres. The UrEpik study. BJU Int. 2003; 92: 409-414.

65. Rosen R, Altwein J, Boyle P, Kirby RS, Lukacs B, Meuleman E, et al. Lower urinary tract symptoms and male sexual dysfunction: the multinational survey of the aging male (MSAM-7). Eur urol. 2003; 44: 637-649.

66. Soliman Y, Meyer R, Baum N. Falls in the Elderly Secondary to Urinary Symptoms. Rev Urology. 2016; 18: 28-32.

67. Hartikainen S, Lönnroos E, Louhivuori K. Medication as a risk factor for falls: critical systematic review. J Gerontol A Biol Sci Med Sci. 2007; 62: 1172 1181.

68. Mets MA, Volkerts ER, Olivier B, Verster JC. Effect of hypnotic drugs on body balance and standing steadiness. Sleep Med Rev. 2010; 14: 259-267. 
69. Berlie, HD, Garwood CL. Diabetes medications related to an increased risk of falls and fall-related morbidity in the elderly. Ann Pharmacother. 2010; 44: 712-717.

70. Agha Z, Lofgren RP, VanRuiswyk, JV, Layde PM. Are patients at Veterans Affairs medical centers sicker? A comparative analysis of health status and medical resource use. Arch Int Med. 2000; 160: 3252-3257.

71. Fritel X, Lachal L, Cassou B, Fauconnier A, Dargent-Molina P. Mobility impairment is associated with urge but not stress urinary incontinence in community-dwelling older women: results from the Ossébo study. BJOG. 2013; 120: 1566-1572
72. Quigley PA, Palacios P, Spehar AM. Veterans' fall risk profile: a prevalence study. Clin Interv Aging. 2006; 1: 169.

73. Department of Veterans Affairs, Office of the Actuary. Veteran Population Projection Model (VetPop2014) [PDF] Department of Veterans Affairs. 2015. 